Hans du Plessis

\title{
Die konsolidasie van die Afrikaanse taalgemeenskap
}

\begin{abstract}
Without trying to distinglish between the subject Afrikaans and the language Afrikaans, and without denying the metaphoric meaning of a statement like 'Afrikaans is oppressive', this anticle investigates the position of Afrikaans among the other ten main languages of South Africa.
\end{abstract}

The idea that Afrikans is a mere minority language in South Africa is repudiated. Statistical figures indicate that Afrikaans is the language with the largest number of speakers and the third largest mother tongue in South Africa. The question as to why Afrikaans is regarded as a minority language - even by its own users - is also touched upon. In this article it is angued that the political system of apartheid has split the language community into two pars and that therefore this community has never been a unity.

The future role of Afrikaans in a democratic South Africa will also be determined by the users of Afrikaans, given that the Afrikaans language community could be consolidated. This aricle argues that the lack of unity within the Afrikaans speech community is mainly the reason for the belief that Afrikaans is, in a statistical sense, a minority language. If the Afrikaans speech community can be consolidated, Afrikaans will be able to take its natural place among the other ten languages of South Africa. Such a consolidation, however, has to be brought about by those who form this community.

\section{Inleiding}

Dit gaan in hierdie artikel om Afrikaans, maar sonder om doelbewus 'n onderskeid tussen die vak en die taal te maak, want die toekoms van die vak is afhanklik van die taal se toekoms en omgekeerd. 'n Ander wisselwerking wat outomaties ter sprake moet kom, en verwarrend kan wees, is die wisselwerking tussen taal en spreker. Wat bedoel 'n mens as jy sê Afrikaans is oorheerserstaal? 'n Taal as sodanig kan nie oorheers nie, 'n taal kan nie haat nie en 'n taal het op sigself selfs nie 'n toekoms nie - net die sprekers kan oorheers of haat of 'n toekoms hê. Dit is daarom so dat dit misleidend kan wees as daar gesê word dat Afrikaans apartheidstaal of bevrydingstaal is. As 'n mens iets van 'n taal sê, bedoel jy by implikasie eintlik iets oor sy mense; Afrikaans kan nie liefhê nie, maar sy mense kan. Die aanname is dus dat wanneer daar in hierdie artikel van Afrikaans gepraat word, dit meestal in oordragtelike sin gebruik word. As Afrikaans 'n toekoms het, het sy sprekers 'n toekoms, en as die taal 'n toekoms het, het die vak 'n toekoms. Kortom: kan 'n mens 'n taal en sy gebruikers afsonderlik beskou? Is die toekoms van die mens te skei van die toekoms van sy taal?

'n Belangrike vraag lê daarin opgesluit: as Afrikaans nie 'n toekoms het nie, beteken dit 
dan noodwendig dat sy sprekers nie 'n toekoms het nie? Gestel Afrikaans word verbied en hou op om te bestaan, sal die sprekers dan nog bly voortbestaan? F:k meen hulle sal bly lewe ja, maar dan seker as 'n ander entiteit, want dit word algemeen aanvaar: taal is ' $n$ merker van identiteit. Aan die ander kant is die verband tussen tatal en gebruiker tog losser: Latyn bestaan vandag nog, maar daar is nie meer Romeine nie. Of: het die Romeine ophou bestaan toe Latyn opgehou het om lewende taal te wees? Of leef Latyn voort in die hedendaagse Romaanse tale?

Die stelling wat ek probeer maak, is dat die verhouding tussen 'n taal en sy sprekers nie so eenvoudig is as wat mense soms wil maak nie. Daarom is die gesprek oor die toekoms van tale ook nie so eenvoudig as wat dit mag lyk nie.

\section{Funksie en status}

Die funksies wat 'n taal vervul, het 'n invloed op die houding wat mense van binne en van buite die taal self teenoor die taal het. Die funksies en die houding het weer 'n direkte invloed op die betrokke taal se status. Eenvoudiger: 'n taal sonder 'n letterkunde is 'n taal wat in die oë van mense 'n mindere status beklee. As Engels byvoorbeeld sy funksie as handelstaal verloor, verloor Engels 'n stuk status. As 'n mens dus sonder meer sê Afrikaans (of watter taal ook al) moet sy funksie as amptelike taal verloor, is jy nie net besig om 'n taalfunksie prys te gee nie, jy is natuurlik besig om fasette van die gebruikers se posisie prys te gee. As dit nie so was nie, sou die amptelike status van Afrikaans in 'n toekomstige Suid-Afrika mos ook nie vir die PAC belangrik gewees het nie. Dan sou dit nie 'n kwessie by die ANC gewees het of Afrikaans sy amptelike status mag behou nie; die ANC sou nie 'n taalplan uitgewerk het nie.

Juis in die lig hiervan is die voorlegging aan Kodesa van die English Academy of Southern Africa soos in die pers berig, naamlik dat Engels die enigste amptelike taal in Suid-Afrika moet word, onbegryplik. Die stel van Engels as enigste amptelike taal getuig van 'n onsensitiwiteit in die proses van onderhandeling en is tog 'n vorm van koloniale arrogansie. So 'n voorstel wat die aansprake, reg of verkeerd, van al tien die ander Suid-Afrikaanse tale eenvoudig ignoreer, herinner nogal sterk aan die werkwyse van die Afrikaanse kultuurorganisasie van die middel-vyftigerjare toe die taalhandhawing as reg tot selfs in die howe gevoer is as iemand byvoorbeeld nie in Afrikaans bedien word nie. Sodra die taalaansprake van meer as tagtig persent ander Suid-Afrikaners genegeer word, volg dit logies dat die mense en die sê van die groot meerderheid Suid-Afrikaners ook genegeer word.

Uit alles wat tot dusver gesê is, kan 'n mens die ou afgesaagde beskuldiging verwag, naamlik dat dit maar weer die paranoïese Afrikaner is wat homself bedreig voel en wat bang is dat hy uit 'n bestaan gedefinieer gaan word, en die vrees probeer wegsteek agter ' $n$ taalbeweging.

Mag ek dit dan duidelik as uitgangspunt stel: ek is nie bevrees vir 'n nuwe Suid-Afrika waarin die Afrikaner nie meer dieselfde politieke mag gaan hê nie. Ek wil ten volle deel wees van 'n demokratiese Suid-Afrika, maar ek eis vir myself die reg op om daarvan deel te wees in my moedertaal (vergelyk ook Du Plessis, 1992).

Hoekom is moedertaal dan so belangrik? sou u kon vra. Met antwoorde sou ek u baie 
lank kon besig hou, maar waarskynlik sal dit voldoende wees as ek u daarvan kon oortuig dat 'n mens jou intellektuele beste in jou moedertaal kan lewer. Die produkte van die gees, die genuanseerde dieptes van die intellek vind in die moedertaal die duidelikste uiting. My diepste self kan ek die maklikste en die beste in my eie taal wees. Die vrye reg van moedertaalgebruik op alle vlakke is een van die hoekstene van die vryheid van die individu en 'n taalbedeling wat nie vir hierdie vryheid voorsiening maak nie, verontagsaam 'n mensereg.

Hierdie reg is uiteraard nie net gesetel in taal se status as amptelike taal nie, want amptelike taal is maar een van die hoë funksies en daar is baie maniere waarop 'n taal ampstaalstatus kan hê. Die geldige volgende vraag sou dus kon wees of 'n taal dan nou amptelike status moet hê om hierdie basiese mensereg uit te voer? Nie noodwendig nie, want om te kan voortbestaan, hoef die taalregte van die betrokke taal nie noodwendig as ampstaal in 'n grondwet beskerm te word nie.

Nou waarom gaan dit dan? Oor die aanvaarding daarvan dat daar sonder meer funksies van 'n taal weggeneem kan word en dan voor te gee dat die taal daarmee saam sonder meer sal bly groei. Geen taalbeplanningsteorie maak daarvoor voorsiening dat 'n taal funksies verloor en dan steeds kan bly groei nie. In die teorie van taalbeplanning word 'n taal se sterkte wat korpus en status betref, bepaal deur drie stelle faktore, naamlik

* die grootte van die taalgemeenskap,

* die funksies wat die taal vervul en

* die houding teenoor die taal. (Vergelyk in hierdie verband Steyn (1980), Verhoef (1991) en Van der Merwe (1989).)

En hierdie drie stelle is so ineengestrengel dat dit soms ononderskeidbaar is.

Dit gaan dus nie daarom of Afrikaans sonder sy status as amptelike taal kan bly voortbestaan nie. Dit gaan eenvoudig daarom dat as Afrikaans nie meer amptelik is nie, die taal dus een van sy hoë funksies verloor: anders as byvoorbeeld Sepedi of Tsonga, word Afrikaans 'n funksie ontneem wat hy tot dusver suksesvol vervul het. Die verlies van 'n hoë funksie van 'n taal móet 'n invloed hê op sy status.

Dat Afrikaans op dieselfde manier amptelike taal moet bly as wat hy dit sedert 1925 is, is nie die argument nie (Du Plessis, 1992:47 e.v.). Daar word eenvoudig geargumenteer dat die verlies van die ampstaalfunksie van enige taal volgens die teorie van taalbeplanning natuurlik 'n statusverlies moet impliseer. Dit is daarom 'n drogredenasie om te sê dat Afrikaans beter daaraan sal toe wees as hy nie meer amptelike taal is nie. Dit maak eenvoudig geen wetenskaplike sin nie. Die verlies van enige funksie van 'n taal kan nie sonder regstellende handeling aan die natuurlike verloop van sake oorgelaat word nie.

Mag ek egter weer sê dat dit nie hier gaan om die behoud van die status quo wat tale in Suid-Afrika betref nie. Dit gaan net daarom dat as Afrikaans nie meer amptelike taal is nie, dan verloor hy 'n belangrike hoë funksie, en dit móet 'n invloed hê, en die taalbeplanner moet daarop reageer. 


\section{Taalbeplanning}

Dat 'n taal se toekoms beplan moet word, is in elk geval nie vreemd nie. Daar is niks anders aan die beplanning van die toekoms van' $n$ taal as sê maar aan die beplanning van die toekoms van die renoster nie. Net so min as wat die renoster vanself in 'n onvriendelike omgewing kan voortbestaan, net so min kan 'n taal vanself by 'n veranderde omgewing aanpas. Taalbewaring is ' $n$ wetenskap soos wat natuurbewaring ' $n$ wetenskap is.

Verder is dit 'n mite dat Afrikaans die enigste taal is wat hom oor oorlewing bekommer. As Engels dan onbekommerd was, hoekom dan die voorstel van die English Academy? As Nederlands vanself sal bly leef, hoekom die simposium op simposium oor Nederlands in die nuwe Europa? As Frans onbepland kan bly bestaan, hoekom dan die voortreflike werk en die enorme begroting van die Alliance Francais? U sien, daar is niks krampagtigs in taalbeplanning nie - daar is niks verdoemends in die gesprek oor die toekoms van Afrikaans nie. Dit is die verdagmaking van verstandige voorkomende beplanning wat moet endkny.

Daar is verder ook iets heel anders in die huidige taalgesprek: anders as in die geval van twee of drie dekades gelede is dit wat my betref nie 'n Afrikaanssentriese handhawingsaksie wat om die mite van taalsuiwerheid gaan nie. Hoeveel Anglisismes en Engelse woorde daar in Afrikaans is, bepaal nie die toekoms van Afrikaans nie. Hoe korrek die taal gebruik word, is nie die toekomsbepaler nie; dit mag hoogstens 'n mindere aspek van korpusbeplanning wees. Dit is 'n normatiewe kwessie wat in hierdie artikel nie ter sprake kom nie. Taalsuiwerheid is in ieder geval 'n mite. Daar bestaan nie iets soos 'n suiwer taal nie (vergelyk Odendal, s.j. 5:76).

Waarom gaan dit dan? Dit gaan om die beplanning van Afrikaans binne 'n Suid-Afrika waarin die wit sprekers van Afrikaans nie meer dieselfde politieke sê gaan hê as wat hulle tot dusver gehad het nie.

\section{Die posisie van Afrikaans}

Ek kan Afrikaans se toekoms bloot beredeneer op grond van feite uit die verlede, die huidige situasie en onseker projeksies oor die toekoms. En die eerste feit waarmee 'n mens rekening móét hou, is die feit dat Afrikaans een van elf mededingers is. Daar is ten minste elf tale in Suid-Afrika ter sprake, want die tyd is verby dat Afrikaans of Engels oor hulle toekomsposisie kan besin sonder inagneming van die feit dat daar nog nege ander SuidAfrikaanse tale is wat op dieselfde gronde dieselfde regte kan opeis. Afrikaans se toekoms is verwe ef met dié van die ander Suid-Afrikaanse tale en as dit in ons beplanning buite rekening gelaat word, is ons besig met die verwoes van 'n toekoms, nie met die bou daarvan nie.

Sodra ons dus van Afrikaans as amptelike taal in die toekoms praat, moet dit gedoen word in die lig van die moontlikheid dat sê maar Zoeloe of Tswana of Venda ook so'n aanspraak mag hê.

Dit gaan egter om 'n Afrikaans met nuwe inhoud! Mag ek dit ook verder duidelik stel dat Afrikaans vir my in hierdie gesprek nie net die standaardtaal mag beteken nie; dit is nie 
net die sogenaamde Algemeen-Beskaafd waarom dit gaan nie. Afrikaans moet ál sy eie dialektiese moontlikhede insluit. Die Afrikaans van die vissersdorp aan die Weskus is gelyk aan die Afrikaans van die Afrikaanse woordelys en spelreëls. Daarby nog moet dit 'n Afrikaans beteken wat histories verder teruggaan as 1875 en die GRA en dit moet 'n Afrikaans wees wat ook die bydrae van sy nie-wit sprekers tot sy eie geskiedenis herken en erken! L.T. du Plessis (1986) gee hiervan 'n deeglike uiteensetting.

Volgens sensusgegewens is meer as die helfte van Afrikaans se moedertaalsprekers nie wit nie, en as Afrikaans nie sy volle momentum in die toekoms kan monster nie, dan het hy logieserwys minder as die helfte kans op voortbestaan.

Afrikaans, soos alle tale ter wêreld, se voortbestaan word bepaal deur die funksies wat hy vervul en deur die grootte van sy taalgemeenskap. Oor die funksies is daar reeds iets gesê, naamlik dat 'n mens nie van die funksies kan wegvat en dan steeds glo die taal groei nie. Ek wil verder veral aandag gee aan die grootte en bydrae van die Afrikaanse taalgemeenskap. Dit kom, eenvoudiger gestel, daarop neer dat 'n taal se voortbestaan direk verband hou met die hoeveelheid mense wat 'n taal gebruik.

Afrikaans is nóg wat sy funksies nóg wat sy getalle betref 'n minderheidstaal. Afrikaans beding dus nie vanuit 'n posisie van onmag vir 'n toekomsplek nie. Afrikaans vervul alle hoë en lae funksies en Afrikaans is die grootste gebruikstaal in Suid-Afrika. Skugter hoef hy dus nie te wees nie. Verder is Afrikaans die derde grootste moedertaal in Suid-Afrika: net Zoeloe en Xhosa het meer moedertaalsprekers as Afrikaans. (Du Plessis, 1992:48. Dit is ook die syfers wat byvoorbeeld deur die LICCA-projek van die Universiteit van Pretoria aanvaar word.)

As daar na die syfers gekyk word, is daar volgens die RGN 13,3 miljoen mense in SuidAfrika wat Afrikaans kan gebruik (ATKV, 1991) - en daarvan het in die omgewing van 6 miljoen dit as moedertaal. As taalgemeenskapsgrootte (dus die hoeveelheid sprekers) dan ' $n$ bepalende faktor vir ' $n$ taal se toekoms is, dan het Afrikaans hieroor nie bekommernis nie.

'n Mens sou hier nog verder kon byvoeg dat Afrikaans se taalgemeenskap ook versterk word deur die miljoene sprekers van Nederlands en Vlaams in Europa.

Inderdaad dan nie so 'n donker prentjie nie: volle funksievervulling en miljoene gebruikers! Wat is dan die probleem?

\section{Taalhouding}

Die probleem lê vasgevang in nietalige faktore: dit lê in die omgewing van die ander stel bepalende faktore, naamlik houding! Nie soseer die houding van ander nie, maar juis die houding van Afrikaans se moedertaalmense! Die algemene hensop-houding van mense, naamlik Afrikaans gaan tog nie in die toekoms bestaan nie; die houding (wat op geen enkele empiriese ondersoek gegrond is nie) dat swart mense dan kwansuis nie wíl Afrikaans praat nie; die houding dat Afrikaans opgeoffer moet word om die sukses van politieke onderhandeling te verseker en die absurde opvatting dat die meeste Afrikaanssprekendes in elk geval Engels kan verstaan. 
Ek vermoed dié wanvoorstellings is almal terug te voer na ons eie koloniale halsstarrigheid; ons eie weiering om Afrikaans en sy mense anders te sien as deur die oë van die wit nasionalisme. Afrikaans is méér as sy wit sprekers. Die gemiddelde Afrikaanse moedertaalspreker is eerder die plaaswerker en die fabriekswerker. En verder: as die swart spreker Afrikaans nie sou wou gebruik nie, hoekom is Afrikaans as skoolvak heringestel in die Transkei, hoekom is dit dan amptelike taal in Bophuthatswana en hoekom neem $96,5 \%$ swart skoolkinders dit dan as keusevak vir matriek?

Die bedreiging van Afrikaans lê dus nie buite Afrikaans nie, dit lê hier binne in ons wat Afrikaans is, dit lê in die Afrikaanssprekende se eie minderwaardigheidsgevoel, in ons eie ongeloof in Afrikaans.

Hoe is dit dan dat 'n taalgemeenskap van 13,3 miljoen sprekers in 'n land van iets oor die 30 miljoen mense homself bedreig voel? Hoekom ervaar die derde grootste moedertaalgemeenskap in Suid-Afrika homself as 'n minderheidstaal?

Waarskynlik omdat die syfers 'n ander deel van die werklikheid nie weergee nie. Kom ons vergeet verder van die sekondêre taalgemeenskap en ons bepaal ons net by die primêre of moedertaalgemeenskap. Daar is in die omgewing van 6 miljoen Afrikaanse moedertaalmense. Met watter gesindheid oor Afrikaans loop die Afrikaanse moedertaalgebruikers die toekoms tegemoet? Die punt is: die toekoms van 'n taal word in hoë mate bepaal deur sy funksies en sy taalgemeenskapsgrootte, maar uiteindelik is dit die houding van sy eie mense wat die deurslag gee.

Hoekom is dit so dat ons wil bly glo Afrikaans het nie 'n kans nie? Ek dink die hoofrede lê in ons eie aanvoeling dat die 6 miljoen moedertaalgemeenskap 'n misleiding is. Dit is ' $n$ misleiding omdat die Suid-Afrikaanse werklikheid tot dusver nie 'n Afrikaanse eenheid toegelaat het nie. Daar mag in totaal meer as 6 miljoen mense wees wat Afrikaans as moedertaal het, maar hierdie 6 miljoen is en was nog nooit 'n eenheid nie, en ek bedoel daarmee dat dit as taalgemeenskap nog nooit 'n eenheid was nie. Dit is die feit dat daar eintlik nie regtig sprake is van 'n Afrikaanse taalgemeenskap nie wat ons onbeskermd laat voel. Daar is nog altyd met net die wit deel van die taalgemeenskap rekening gehou as dit oor die handhawing van Afrikaans gegaan het.

Die kultuurgeorganiseerde Afrikaner het hulle aksies vanuit die kern van die wit Afrikaanse moedertaalmens geloods, en dit was ook net op hierdie gedeelte van die taalgemeenskap gerig. Hierdie benaderingswyse het daartoe gelei dat die bruin moedertaalspreker uit die voortbestaansgesprek gedefinieer is. Die politieke oorsaak en gevolg daarvan is nie ter sprake nie. Al wat ter sprake is, is die feit wat hieruit voortspruit, naamlik dat die momentum van die primêre Afrikaanse taalgemeenskap net halfpad so groot is as wat hy kan wees, en as wat die statistiek onverwerk voorgee.

Hierdie breuk in die moedertaalgemeenskap moet oorbrug word as Afrikaans met die stem wil praat wat hy inderdaad het! Taalbeplanning in Afrikaans moet daarom

* rekening hou met die feit dat Afrikaans een van elf gelykwaardige tale is, maar

* dit moet ook voorsiening maak vir die konsolidasie van die Afrikaanse moedertaalgemeenskap en

* dit moet aksies kan loods waarby alle Afrikaanssprekendes betrokke kan en wil raak. 
Dit is hoofsaaklik op grond van die bestaande geskeidenheid van die taalgemeenskap dat Afrikaans as minderheidstaal ervaar kan word. Die vraag is egter of daar nie 'n manier is om dié geskeidenheid te oorbrug nie? Dit lyk of die bestaande Afrikaanse kultuurorganisasies dit nie kan regkry nie. Sou dit in die lig hiervan nie moontlik wees om alle Afrikaanse moedertaalmense te betrek by iets soos ' $n$ Afrikaanse vereniging wat oor politieke grense heen kan funksioneer nie? Dit veronderstel 'n Afrikaanse vereniging waarbinne dit gaan om die welsyn van Afrikaans.

So 'n gekonsolideerde vereniging sal 'n gekonsolideerde stem vir Afrikaans kan wees. So 'n eenheid kan Afrikaans in sy volheid laat meepraat in die taalgesprek, maar dit moet dan 'n taaleenheid wees wat Afrikaanssprekendes vanuit alle groepe, ook alle politieke groepe, saamtrek ter wille van die regmatige toekomsplek van Afrikaans. Binne so 'n eenheid is Afrikaans dan juis méér as standaardtaal en meer as kombuistaal: dit is die taal van moontlikhede, die taal wat 'n brug tussen Afrika en Europa kan slaan. As eenheid is Afrikaans taal van én onderdrukking én bevryding, taal van die ou en die nuwe SuidAfrika. Die gekonsolideerde taalgemeenskap kan die Afrikaans van die Uniegebou en dié van die Richtersveld versoen. Dit is die Afrikaans van insluiting en nie van uitsluiting nie.

\section{Slot}

Dan, en net dan, het Afrikaans 'n toekoms voor hom wat blink en ver is. Hierdie nuwe Afrikaans en sy mense is bepalend deel van 'n toekoms waarin die Afrikaanse mond ook sy sê moet bly sê.

Maar dit is ook die Afrikaanssprekende wat self die aandeel van Afrikaans in 'n SuidAfrika wat anders lyk, kan bepaal. Ons wat Afrikaans is, gaan die toekomsposisie van Afrikaans en sy mense in hierdie land help bepaal. Dit is die uitdaging vir Afrikaans en al sy mense.

\section{Bronnelys}

ATKV, 1991. 13,3 miljoen redes om Afrikaans te praat Johannesburg : ATKV.

Du Plessis, H. 1992. En nou, Afrikaans? Pretoria : J.L. van Schaik.

Du Plessis, L.T. 1986. Afrikaans in beweging. Bloemfontein : Patmos.

Odendal, F.F. s.j. Aspekte van taal. Kaapstad : Nasou.

Stcyn, J.C. 1980. Tuiste in eie taal. Kaapstad : Tafelberg.

Van der Mcrwe, E.G. 1989. Die ontwikkeling stand en toekoms van Afrikaans in SWA/Numibië. Ongcpublisecrde proefskrif. (D. Litt. - PUCHO.)

Vcrhocf, M.M. 1991. Die stand en toekoms van taalbeplanning in Afrikaans in 'n multitalige Suid-Afrika. Ongcpublisecrde procfskrif. (D. Litt. - PUCHO.)

Potchcfstroomse Universiteit vir CHO 